\title{
Experimental Verification of Interfacial Strength Effect on the Mechanical Properties of Carbon Fiber-Epoxy Composite
}

\author{
Bentang Arief Budiman"*, Firman Bagja Juangsa ${ }^{\$}$, Muhammad Aziz ${ }^{+}$, Ignatius Pulung Nurprasetio*, \\ Ilman Nuran Zaini ${ }^{\&}$ \\ ${ }^{\#}$ Faculty of Mechanical and Aerospace Engineering, Institut Teknologi Bandung, Ganesha street no. 10, Bandung 40132, Indonesia \\ E-mail: bentang@ftmd.itb.ac.id
} *National Center for Sustainable Transportation Technology, Institut Teknologi Bandung, Ganesha street no. 10, Bandung 40132, Indonesia
E-mail: bentang @ftmd.itb.ac.id

${ }^{\$}$ Department of Mechanical Sciences and Engineering, Tokyo Institute of Technology, 2-12-1 Ookayama, Meguro, Tokyo 152-8550, Japan E-mail: juangsa.f.aa@m.titech.ac.jp

${ }^{+}$Institute of Innovative Research, Tokyo Institute of Technology, 2-12-1 Ookayama, Meguro, Tokyo 152-8550, Japan E-mail:aziz.m.aa@m.titech.ac.jp

${ }^{\&}$ Energy and Furnace Technology Division, KTH Royal Institute of Technology, Brinellvägen 8, 11428 Stockholm, Sweden E-mail:zaini@kth.se

\begin{abstract}
The effects of carbon fiber-epoxy interfacial strength on the mechanical properties of the corresponding fiber-matrix composites are experimentally demonstrated in this work. Two composites containing different carbon fibers were tested: as-received fibers and fibers soaked in acetone to remove adhesive on their surfaces. The fiber surfaces were first characterized by scanning electron microscopy and time-of-flight secondary-ion mass spectrometry to verify removal of the adhesive. Further, single-fiber fragmentation tests were conducted to evaluate the fiber strength and the interfacial strength. The mechanical properties of the composites were evaluated via tensile testing under longitudinal and transverse loadings. The results show that interfacial strength does not decrease the mechanical properties of the composites under longitudinal loading. In contrast, under transverse loading, the interfacial strength significantly decreases the mechanical properties, specifically the ultimate tensile strength and toughness of the composites.
\end{abstract}

Keywords — interfacial strength; mechanical properties; fiber-matrix composite; tensile test

\section{INTRODUCTION}

The mechanical properties of fiber-matrix composites have been predicted to be affected by not only the mechanical properties of their constituents but also the constituents' interfacial properties [1]. Interfacial properties, particularly interfacial strength $\left(t_{o}\right)$, determine the effectiveness of stress transfer from the fiber to the matrix and vice versa, which is directly related to the mechanical properties of such composites [2], [3]. Numerous studies have predicted that a low $t_{o}$ can result in fiber-matrix composites with poor mechanical properties [4], [5]. However, the literature contains few studies that have directly verified the effects of $t_{o}$ on the mechanical properties of fiber-matrix composites.

Fig. 1a shows the components of fiber-matrix composite at the micro-level. Here, the interface is considered an important component that should be carefully characterized [6]-[8]. The $t_{o}$ is usually evaluated by a micro-scale testing method such as the single-fiber fragmentation test (SFFT) [9], [10], the push-out test [11], the pull-out test [12], or the micro-bond test [13]. The primary purpose of such evaluations is to elucidate the effectiveness of fiber surface treatments with respect to increasing $t_{o}$ [14]. Researchers have reported substantial improvements of $t_{o}$ as a result of various surface treatment techniques, indicating that such improvements might improve the mechanical properties of fiber-matrix composites.

The mechanical properties of composites have been directly evaluated using tensile tests for ply composite specimens under both longitudinal and transverse loadings as shown in Fig. 1b and 1c. Depending on loading condition, 
the failure mechanisms of the composites might be different. Under longitudinal loading, fiber is firstly broken followed by interfacial cracking or matrix cracking depending on the strength and fracture toughness of them [19]. In contrast, those cracks might firstly appear under transverse loading, which remains the fibers that do not bear the loading. In both longitudinal and transverse loading conditions, $t_{o}$ surely determines the failure mechanisms, which directly affects the mechanical properties of the composites.

Substantial analytical and numerical studies have been conducted to elucidate the micro-level effects of $t_{o}$ on the ply-level mechanical properties of fiber-matrix composites; these studies have focused on modeling the relationship between micro-mechanics and macro-mechanics [15]. Such studies can be conducted by analyses involving homogenization techniques [16]-[18]. By using these techniques, researchers can predict the effects of local micro-scale cracks at the interface on the mechanical properties of composites. Although these techniques appear to be promising for explaining the effect of $t_{o}$ on the mechanical properties of fiber-matrix composites, the experimental validation of these techniques is still a challenging problem due to the scaling difference of evaluations between $t_{o}$ and mechanical properties of the composites. Limited experimental studies on the investigation of the relationship between $t_{o}$ and mechanical properties of the composite were previously conducted in which micro and ply levels are simultaneously analyzed. As a consequence, the high $t_{o}$ values achieved using the previously reported fiber surface treatments are questionable because such treatments have not been demonstrated to positively affect the mechanical properties of fiber-matrix composites. Indeed, direct verification must be obtained via experiments in which the $t_{o}$ and the mechanical properties of fiber-matrix composites are simultaneously evaluated.

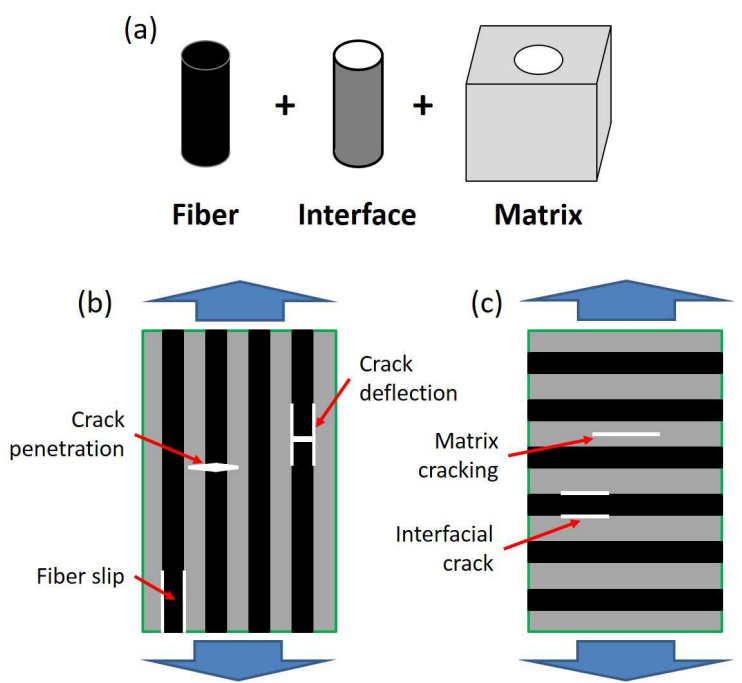

Fig. 1 Components of composite structures at the micro level (a) and illustrations of longitudinal loading (b) and transverse loading (c) applied to ply composites

In the present work, the effect of $t_{o}$ was investigated experimentally. Two composites containing carbon fibers with different surface treatments were tested. The fiber surfaces were first characterized by scanning electron microscopy (SEM) and time-of-flight secondary-ion mass spectrometry (TOF-SIMS) [20]. The $t_{o}$ and fiber strength $\left(\sigma_{f}\right)$ were evaluated using SFFT. The mechanical properties of the ply fiber-matrix composites were then evaluated using tensile tests. The specimens were subjected to longitudinal and transverse loadings. In addition, the effects of $t_{o}$ on the mechanical properties are comprehensively discussed.

\section{MATERIAL AND METHOD}

\section{A. Characterization of the Fiber Surface}

Two types of carbon fibers HTA 40 (TOHO Tenax Co. Ltd.) with different surface treatments were prepared. The first type was as-received carbon fibers obtained from the manufacturer which contain adhesive material on their surface. The second type was carbon fibers conditioned by being soaked in acetone for more than 5 hours and then rinsed with water. This treatment was conducted to remove any adhesive material on the carbon fiber surface.

The surface roughness of both carbon fibers was observed by using SEM. The purpose is to clarify alterations of the roughness due to the surface treatment. Further, TOF-SIMS analysis to verify that the adhesive material had been removed after the surface treatment was also conducted. The positive secondary ion mode was selected to investigate the material compound in the as-received and conditioned fiber surfaces. The positive ion has high sensitivity to hydrocarbon molecules that might be attached to the fiber surfaces during sizing process. These molecules aim to form strong bonding between carbon fiber and polymer matrix such as epoxy.

The $\sigma_{f}$ and the $t_{o}$ were subsequently evaluated by SFFT. The SFFT specimens contained single carbon fiber surrounded by epoxy (Konishi Chemical Co. Ltd). A shear lag model proposed by Kelly-Tyson was used to evaluate $\sigma_{f}$ and $t_{o}$ according to the equations shown in Equations 1 and 2, respectively [21]:

$$
\begin{gathered}
\sigma_{f}=\sigma_{o}\left(\frac{L_{o}}{L_{c}}\right)^{1 / m} \\
t_{o}=\frac{\sigma_{f} d}{2 L_{c}}
\end{gathered}
$$

where $\sigma_{o}$ is the characteristic stress at which fiber cracks appear, $L_{o}$ is the measured area, $L_{c}$ is the critical length, $m$ is the Weibull modulus, and $d$ is the diameter of the fibers. Details of the SFFT procedure are described elsewhere [10].

\section{B. Tensile Testing}

The tensile testing specimens used in this study were prepared using the carbon fibers previously characterized and the epoxy produced by Konishi chemical Co. Ltd. Ply composite specimens for tensile testing were prepared using the hand lay-up technique [22]. The specimens were designed to have low fiber volume fractions of $20 \%$ to ensure that the fiber surface appropriately contacted the matrix. Thus, the experimental results reflect the effects of $t_{o}$. Fig. 2 shows the dimensions of the specimens for tensile testing. The specimens exhibit a uniform fiber direction; they were cut for longitudinal and transverse loading tests. 


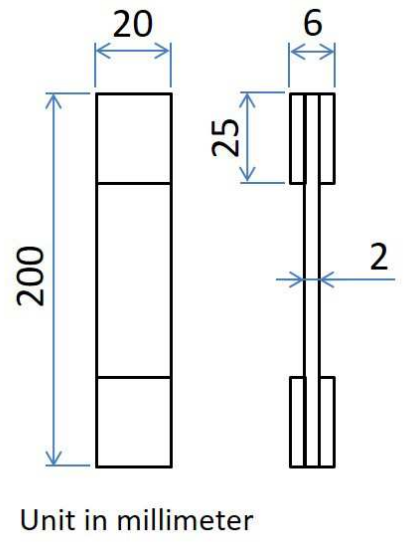

Fig. 2 Schematic showing the specimen dimensions

The detailed scenarios for tensile testing are reported in Table 1. An Instron tensile testing machine was used with a maximum load of $10 \mathrm{kN}$. A tensile speed of $2 \mathrm{~mm} / \mathrm{min}$ at room temperature was applied to all specimens. The load and the displacement were recorded simultaneously until the specimen was broken. The stress-strain curve for each specimen was then obtained from the load-displacement results. From the curve, mechanical properties of the composite were analyzed.

TABLE I

TEnsile Testing ScEnARIos

\begin{tabular}{|l|l|l|}
\hline Loading type & $\begin{array}{l}\text { As-received fiber- } \\
\text { epoxy composite }\end{array}$ & $\begin{array}{l}\text { Conditioned fiber- } \\
\text { epoxy composite }\end{array}$ \\
\hline $\begin{array}{l}\text { Transverse } \\
\text { loading }\end{array}$ & $\begin{array}{l}3 \text { specimens (A1, } \\
\text { A2, A3) }\end{array}$ & $\begin{array}{l}\text { 3 specimens (B1, } \\
\text { B2, B3) }\end{array}$ \\
\hline $\begin{array}{l}\text { Longitudinal } \\
\text { loading }\end{array}$ & $\begin{array}{l}3 \text { specimens (A4, } \\
\text { A5, A6) }\end{array}$ & $\begin{array}{l}3 \text { specimens (B4, } \\
\text { B5, B6) }\end{array}$ \\
\hline
\end{tabular}

\section{RESULTS AND DISCUSSION}

\section{A. SEM Observation}

The SEM micrographs are shown in Fig. 3. Figs. 3a and $3 \mathrm{~b}$ clearly show that the surfaces of both the as-received fibers and the conditioned fibers have uniform porosities parallel to the fiber direction. These uniform porosities are possibly formed during the manufacturing process of the fibers. Later on, manufacturing the composite, the epoxy can fulfill these porosities that can create mechanical locking between the fibers and the matrix and increase $t_{o}$. Figs. $3 \mathrm{c}$ and $3 \mathrm{~d}$ show SEM micrographs of the cross-sectional area of both the as-received fibers and the conditioned fibers. The surface roughness of both fibers was mostly unchanged, which means that the $t_{o}$ due to mechanical locking might be retained even after the fibers' surface was soaked in acetone.

\section{B. TOF-SIMS Analysis}

The TOF-SIMS spectra are shown in Fig. 4. The intensity of the hydrocarbon peaks in the 20-60 Da range was substantially lower in the spectrum of the conditioned fiber surface compared with that in the spectrum of the asreceived fiber surface. In particular, the peak intensities associated with $\mathrm{C}_{2} \mathrm{H}_{\mathrm{n}}^{+}$in the range from 27 to $30 \mathrm{Da}, \mathrm{C}_{3} \mathrm{H}_{\mathrm{n}}^{+}$ in the range from 39 to $44 \mathrm{Da}$, and $\mathrm{C}_{4} \mathrm{H}_{\mathrm{n}}{ }^{+}$in the range from 52 to 57 Da drastically decreased [23].
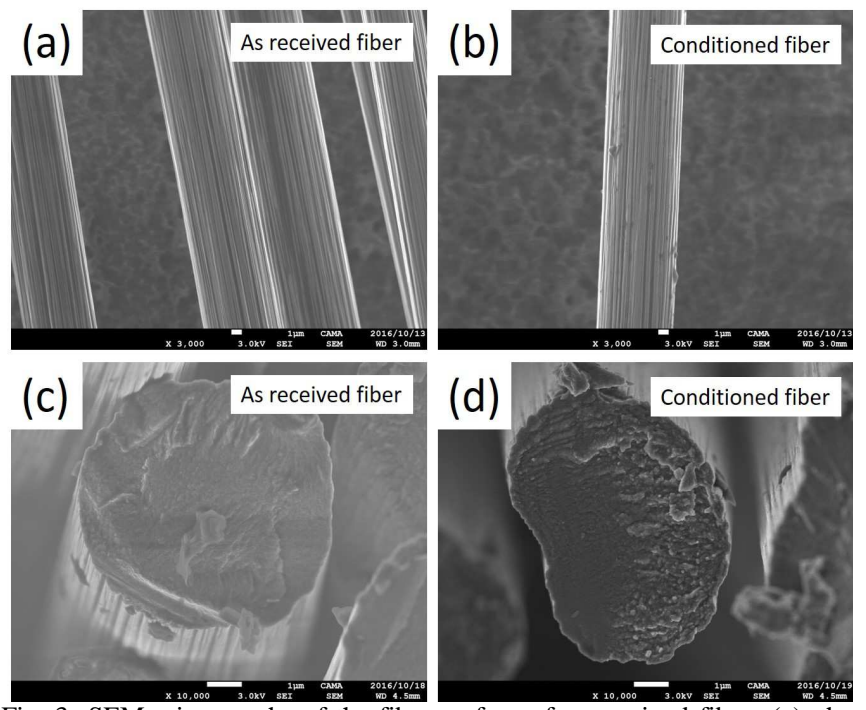

Fig. 3 SEM micrographs of the fiber surface of as-received fibers (a), the conditioned fibers (b), and the cross-sections of the as-received fibers (c) and the conditioned fibers $(\mathrm{d})$

(a)

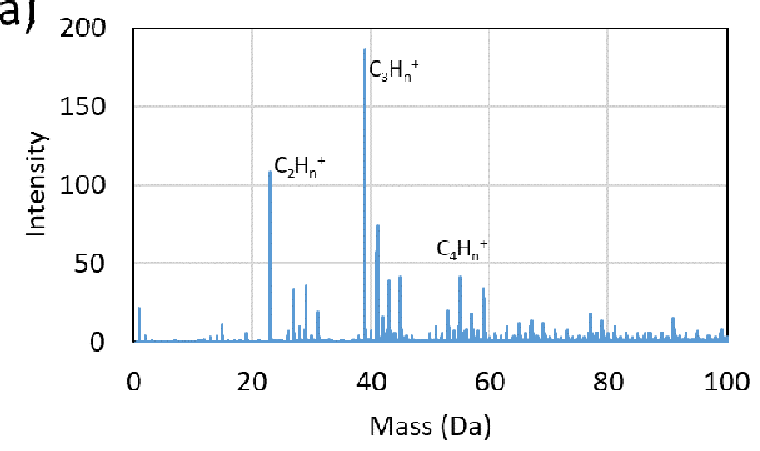

(b)

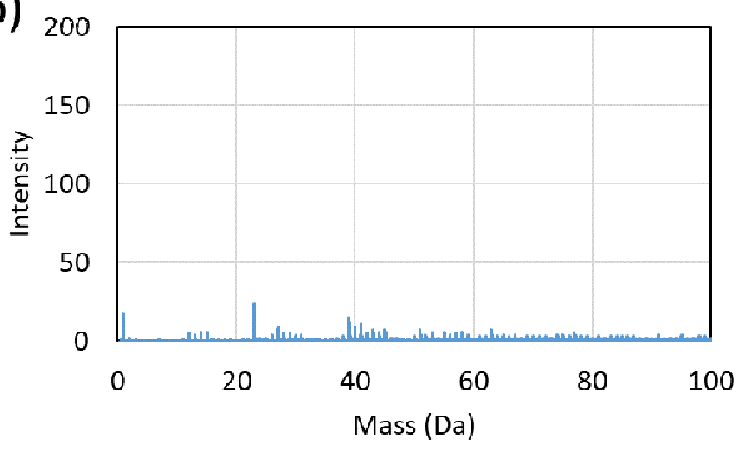

Fig. 4 TOF-SIMS spectra for the as-received fibers (a) and conditioned fibers (b). The decreased intensity of peaks in the range from 20 to $60 \mathrm{Da}$ indicates that the hydrocarbon at the interface was eliminated

The presence of these peaks in the mass spectrum of the as-received fiber surface indicates that an adhesive material containing hydrocarbon molecules was added during the sizing process. It is noted that the exact adhesive compounds are secretly kept by the fiber manufacturer. However, after the fiber was soaked in acetone, no such hydrocarbon content was detected by TOF-SIMS analysis, which indicates that the acetone treatment successfully removed the adhesive. This observation also confirms that the effects of chemical bonding and mechanical locking on $t_{o}$ can be practically separated by soaking the fiber in acetone to remove the adhesive material. 


\section{SFFT Results}

Fig. 5 shows the $\sigma_{f}$ and $t_{o}$ values determined from the SFFT results. After the fibers were soaked in acetone, the values of the $\sigma_{f}$ and the $t_{o}$ decreased approximately $20 \%$ and $50 \%$, respectively. Although the adhesive material was removed from the specimen with conditioned fibers, the low $t_{o}$ still remains. Considering the fibers mainly contain stable carbon compound which is difficult to be reacted with another compound, a plausible explanation of the remaining $t_{o}$ comes from a mechanical locking that prevents shearingmode crack formation at the interface. The mechanical locking is most likely induced by surface roughness, which remains after the surface treatment, as observed in the SEM images in Fig. 3. Furthermore, by assuming that the stiffness of the fibers $\left(E_{f}\right)$ did not change in response to the surface treatment and assuming that the fiber behavior was linear elastic, we calculated the fiber toughness $\left(U_{f}\right)$ using Equation 3:

$$
U_{f}=\frac{\sigma_{f}^{2}}{2 E_{f}}
$$

where the value of $E_{f}$ is $240 \mathrm{GPa}$, as obtained from the TOHO Tenax Co. Ltd. data sheet. Thus, $U_{f}$ values of 48 $\mathrm{kJ} / \mathrm{mm}^{3}$ for the as-received fibers and $30 \mathrm{~kJ} / \mathrm{mm}^{3}$ for the conditioned fibers were obtained using Equation 3. The $U_{f}$ decreased by approximately $37.5 \%$ after the acetone treatment, which indicates that the adhesive material also substantially contributed to the value of $U_{f}$.

(a)

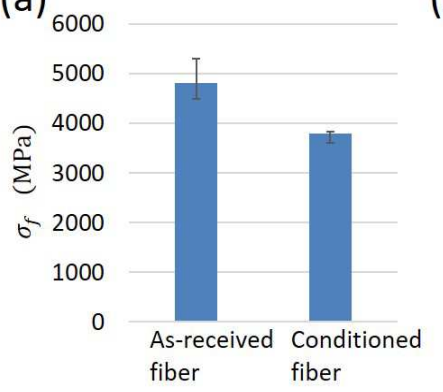

(b)

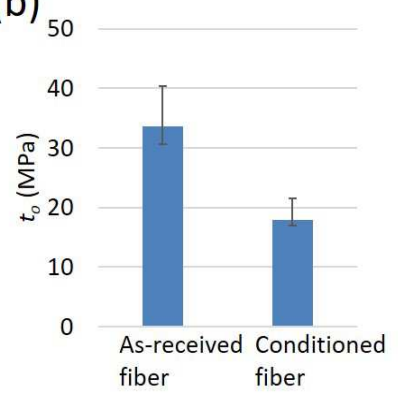

Fig. 5 Fiber strength (a) and interfacial strength (b) for the as-received and conditioned fibers [10]

\section{Stress-Strain Curves}

Stress-strain curves for tensile testing under longitudinal and transverse loadings are shown in Figs. 6 and 7, respectively. The stress-strain curves for three specimens of both the as-received and conditioned fibers show relatively consistent results. In the case of transverse loading testing, nonlinear stress-strain curves that might be caused by the epoxy properties were obtained for both the as-received fibers and the conditioned fibers. These results confirm that nonlinear behavior of the epoxy plays a dominant role in determining the mechanical properties of the composite in the transverse loading direction. Furthermore, the stressstrain curves of the specimens with conditioned fibers decreased to $50 \%$. This result indicates that $t_{o}$ strongly affects the mechanical properties of the composite under transverse loading. Considering the composite subjected to transverse loading is always to be the weakest condition, the $t_{o}$ unavoidably determines the overall performance of the composite as load-bearing structures.
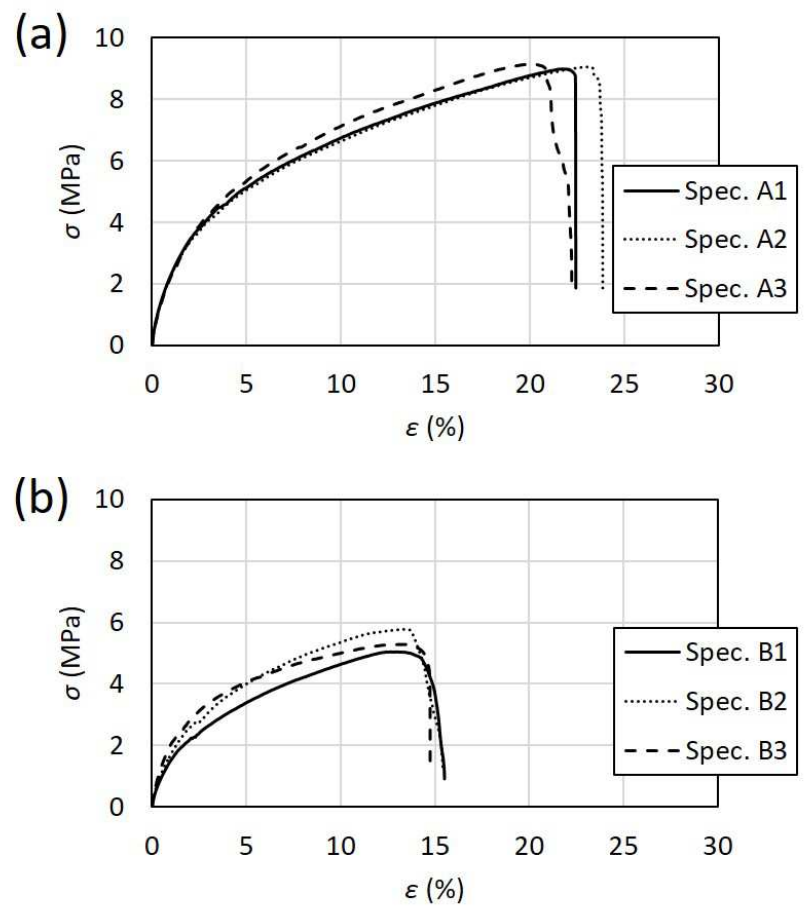

Fig. 6 Stress-strain curves of the as-received fiber-epoxy composite (a) and the conditioned fiber-epoxy composite (b) tested under transverse loading
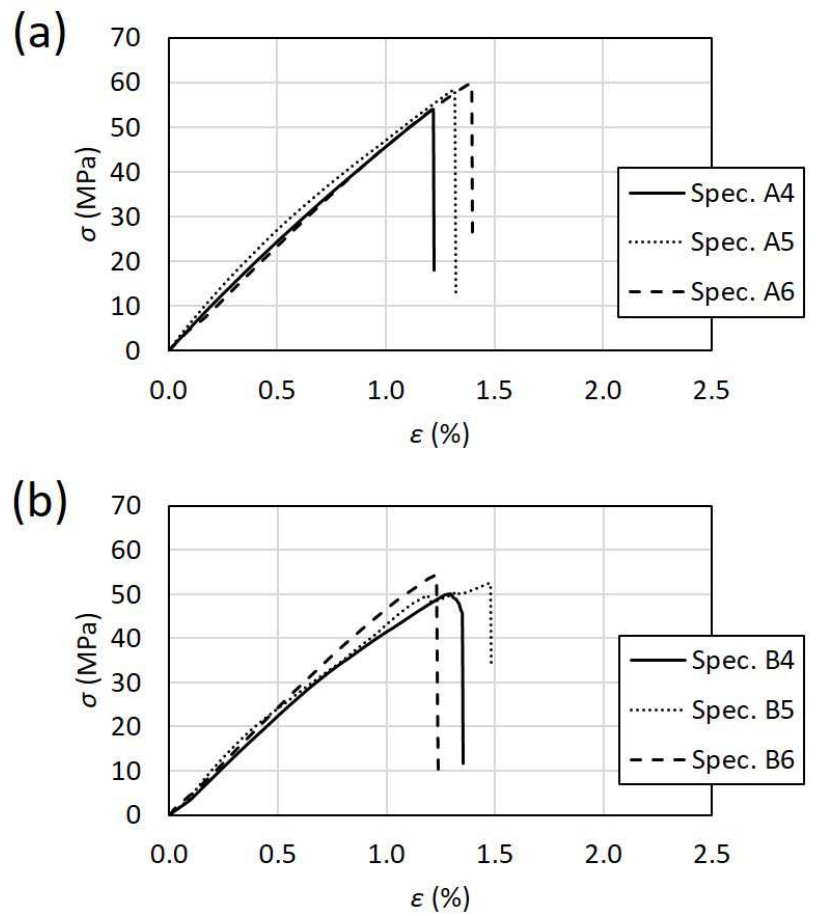

Fig. 7 Stress-strain curves of the as-received fiber-epoxy composite (a) and the conditioned fiber-epoxy composite (b) tested under longitudinal loading

The tensile test results for the composite under longitudinal loading differed slightly from those for the composite under transverse loading. As evident in Fig. 7, linear stress-strain curves were obtained from tensile testing results of specimens with both as-received fibers and 
conditioned fibers. These results are related to the linear behavior of the fibers, which dominantly affect the curves. Under longitudinal loading, the $t_{o}$ did not substantially decrease the mechanical properties of the composite. Notably, however, the elastic modulus of the composite also slightly changed, which might be caused by ineffective stress transfer between the matrix and the fibers [3].

\section{E. Alteration of Mechanical Properties}

The mechanical properties, i.e., the ultimate tensile strength $\left(\sigma_{u t s}\right)$ and toughness $(U)$, of the composites under longitudinal and transverse loadings were calculated on the basis of the stress-strain curves obtained via tensile tests. outs refers to the maximum stress that appears in the curves, whereas $U$ is defined as a total area under the curves. The calculated values of $\sigma_{u t s}$ and $U$ are then plotted in Figs. 8 and 9 , respectively.

Fig. 8 clearly shows that the $\sigma_{u t s}$ under longitudinal loading was only slightly changed. This result is explained on the basis of the mechanism of composite failure under longitudinal loading, where fiber breakage might first occur. Before fiber breakage, the interface does not usually bear relatively high stress; thus, fractures at the interface are avoided. In fact, whether a decrease in $\sigma_{u t s}$ is caused by a low $t_{o}$ or by a low $\sigma_{f}$ is uncertain because, under the longitudinal loading condition, fracture occurs via the shearing mode, which can cause mechanical locking that generates additional $t_{o}$. The effect of mechanical locking becomes more dominant for rough fiber surfaces. By contrast, $\sigma_{u t s}$ under transverse loading drastically decreases as a consequence of a low $t_{o}$ because the interface bears high stress to transfer the load from the matrix $t_{o}$ the fiber. At this stage, $t_{o}$ plays a very important role and can directly determine $\sigma_{u t s}$. The opening mode of fracture at the interface might also contribute to a decrease in $\sigma_{u t s}$, where the mechanical locking does not effectively prevent fracture of the interface.

As shown in Fig. 9, $U$ exhibits tendencies similar to those observed for $\sigma_{u t s}$. The $U$ drastically decreases under transverse loading because the loading cannot be transferred from the matrix $t_{o}$ the fibers as a consequence of a weak interface. Thus, the fibers cannot be deformed to absorb the strain energy from external loading. However, $U$ only slightly decreases under longitudinal loading because the fibers are deformed and broken, resulting in the strain energy from the external loading being absorbed. This result is interesting because low to might not substantially cause low $U$.

Under the scenario of composite failure, after cracks form in the fibers, a low $t_{o}$ can cause the cracks to first deflect at the interface before penetrating into the matrix. However, a high to causes the cracks to directly penetrate into the matrix. Consequently, the surface area of the cracks generated as a result of a low $t_{o}$ is much larger than that of the cracks generated as a result of a high $t_{o}$, which means the absorbed energy required $t_{o}$ create the cracks is substantially greater in the case of a low $t_{o}$. The slight decrease of $U$ might only be caused by the decrease of $U_{f}$ in response to the surface treatment rather than by a low $t_{o}$.

We also note that according to Fig. 9, the values of $U$ are much higher when the composite is subjected to transverse loading rather than longitudinal loading. This result arises from the ductile properties of the matrix, which enables the absorption of strain energy via matrix deformation. Under longitudinal loading, the fiber cracks cause stress concentration in each point of the composite, which in turn causes the composite to break under the low strain. Thus, the total strain energy absorbed by the composite is relatively low.

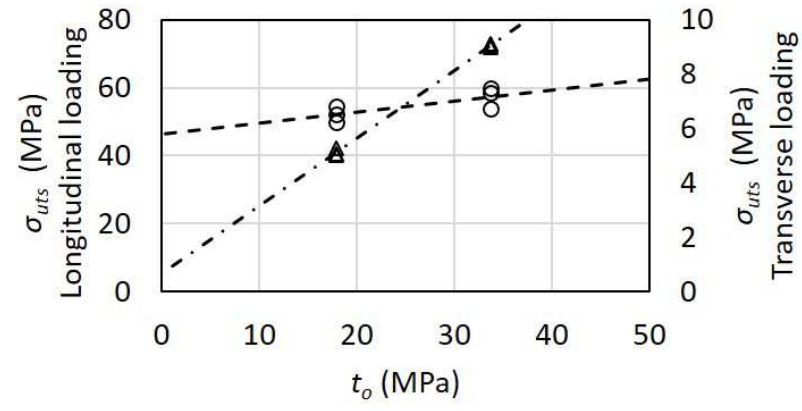

O Longitudinal loading $\Delta$ Transverse loading

Fig. 8 Tensile strength of the composite versus interfacial strength

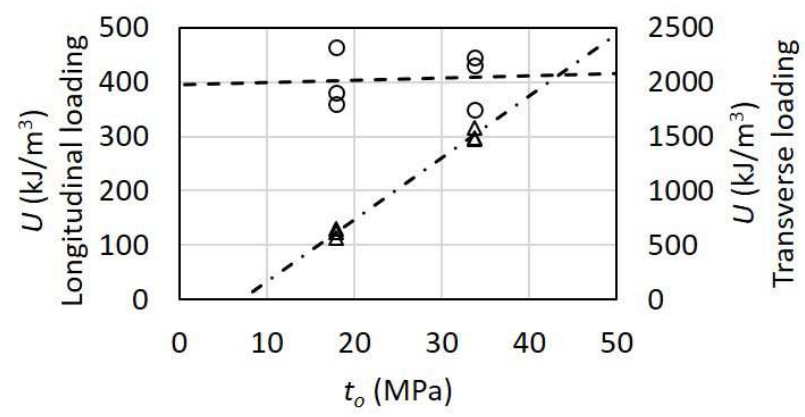

OLongitudinal loading $\Delta$ Transverse loading

Fig. 9 Toughness of the composite versus interfacial strength

On the basis of these experimental results, $t_{o}$ is demonstrated to strongly affect the mechanical properties of carbon fiber-epoxy composite, i.e., its $\sigma_{u t s}$ and $U$, particularly under transverse loading. Low $t_{o}$ can drastically decrease the $\sigma_{u t s}$ and $U$. In contrast, the role of $t_{o}$ under longitudinal loading is still questionable. Depending on the failure mechanisms, low $t_{o}$ might give benefit to the mechanical properties of the composite because the deflection of fiber crack to the interface prior matrix cracking can increase the strain energy absorption, which delays final failure of the composite. However, when the interfacial cracks appear prior fiber breaks, which is possible for the extremely small $t_{o}$, slip failure mechanism at the interface might occur that causes the mechanical properties of the composite drastically decrease.

In the engineering applications, the composite is also designed for absorbing the strain energy as much as possible such as for crashworthiness structures and for blast impact protectors. In these cases, the defects of the composite structures cannot be avoided since the load imposed to the structures is much larger than $\sigma_{u t s}$. In the context of the design problem for this case, increasing $U$ of the composite is more beneficial than the $\sigma_{u t s}$. Thus, the $t_{o}$ should not be too high for allowing the fiber crack deflected to the interface. In 
general, controlling $t_{o}$ values in the manufacturing process of the composite is important to meet requirements of the design structures.

\section{CONCLUSIONS}

The effect of interfacial strength on the mechanical properties of a fiber-matrix composite was revealed. The interfacial strength strongly affected the composite under applied transverse loading: the ultimate tensile strength and toughness of the composite decreased by $50 \%$ when the interfacial strength was decreased $50 \%$. This relationship might be a consequence of the failed transfer of the load from the matrix to the fibers, rendering the fibers unable to effectively participate in bearing the load and resulting in the appearance of cracks at the interface under low loading. By contrast, the mechanical properties of composites under longitudinal loading only slightly changed in response to changes in interfacial strength because the failure scenario of the composite under longitudinal loading allows fibers to break before cracks occur at the interface or in the matrix. The diminished mechanical properties of the composite are mostly caused by poor mechanical properties of fibers owing to the surface treatment. The role of interfacial strength in determining the mechanical properties of the composite was confirmed in this study.

\section{ACKNOWLEDGMENT}

We would like to thank the Center of Advanced Material Analysis Tokyo Institute of Technology for facilitating SEM and TOF-SIMS analyses.

\section{REFERENCES}

[1] S. Ben, J. Zhao, Y. Zhang, Y. Qin, and T. Rabczuk, "The interface strength and debonding for composite structures: Review and recent developments," Composite Structures, vol. 129, pp. 8-26, 2015.

[2] G. Simeolia, D. Aciernoa, C. Meolab, L. Sorrentino, S. Iannace, and P. Russoc, "The role of interface strength on the low velocity impact behaviour of PP/glass fibre laminates," Composites Part B: Engineering, vol. 62, pp. 88-96, 2014.

[3] B.A. Budiman, F. Triawan, F. Adziman, and I.P. Nurprasetio, "Modelling of Stress Transfer Behavior in Fiber-Matrix Composite 1 under Longitudinal and Transverse Loadings," Composite interfaces, vol. 24, pp. 677-690, 2017.

[4] N. Ichinose, M. Ishikawa, and K. Morimoto, "Effect of stress transfer between fiber and matrix on toughness of polymer composite," Polymer Composite, vol. 32, pp. 1617-1624, 2011.

[5] M. Shioya, S. Yasui, and A. Takaku, "Relation between interfacial shear strength and tensile strength of carbon fiber/resin composite strands," Composite interfaces, vol. 6, pp. 305-323, 1998.

[6] Z. Serge and M. Edith, "Characterization of fiber/matrix interface strength: applicability of different tests, approaches and parameters," Composite science and technology, vol. 65, pp. 149-160, 2005.
[7] B. Haspel, C. Hoffmann, P. Elsner, and K.A. Weidenmann, "Characterization of the interfacial shear strength of glass-fiber reinforced polymers made from novel RTM processes," International Journal of Plastic Technology, vol. 19, pp. 333-346, 2015.

[8] B. A. Budiman, K. Takahashi, K. Inaba, and K. Kishimoto. "A new method of evaluating interfacial properties of a fiber/matrix composite," Journal of Composite Materials, vol. 49, pp. 465-75, 2015 .

[9] J.M. Rich and L.T. Drzal, "Round robin assessment of the single fiber fragmentation test," In: Proceedings of the American society for composites 17th technical conference. Indiana, 21-23 October 2002. p. 1-10.

[10] B.A. Budiman, D. Suharto, K. Kishimoto, F. Triawan, K. Takahashi, and K. Inaba, "Single Fiber Fragmentation Test for Evaluating FiberMatrix Interfacial Strength: Testing Procedure and Its Improvements," In: Proceedings of 15th Seminar Nasional Tahunan Teknik Mesin. Bandung, 5-6 October 2016. p. 809-816.

[11] N. Chandra and H. Ghonem. "Interfacial mechanics of push-out tests: theory and experiments," Composites Part A: Applied Science and Manufacturing vol. 32, pp. 575-584, 2001.

[12] C.Y. Yue, H.C. Looi, and M.Y. Quek. "Assessment of fibre-matrix adhesion and interfacial properties using the pull-out test Author links open the overlay panel," International Journal of Adhesion and Adhesives, vol. 15, pp. 73-80, 1995.

[13] M. Nishikawa, T. Okabe, K. Hemmia, and N. Takeda, "Micromechanical modeling of the microbond test to quantify the interfacial properties of fiber-reinforced composites," International Journal of Solids and Structures, vol. 45, pp. 4098-4113, 2008.

[14] J.K. Kocsis, H. Mahmood, and A. Pegoretti, "Recent advances in fiber/matrix interphase engineering for polymer composites," Progress in Materials Science, vol. 73, pp. 1-43, 2015.

[15] G. Han, Z. Guan, Z. Li, M. Zhang, T. Bian, and S. Du. "Multi-scale modeling and damage analysis of composite with thermal residual stress," Applied Composite Materials, vol. 22, pp. 289-305, 2015.

[16] F. Greco and G. Sgambitterra, "Validation of Homogenization Techniques for Locally Periodic Fiber-Reinforced Composites with Interfacial Debonding," Mechanics of Advanced Materials and Structures 2013, 20(8), 638-651.

[17] R. Azizi, C.F. Niordson, and B.N. Legarth, "On the Homogenization of Metal Matrix Composites using Strain Gradient Plasticity," Acta Mechanica Sinica, vol. 30, pp. 175-190, 2014.

[18] F. Lebona, S. Dumonta, R. Rizzonic, J.C. López-Realpozod, R. Guinovart-Díazd, R. Rodríguez-Ramosd, J. Bravo-Castillerod, F.J. Sabinae, "Soft and hard anisotropic interface in composite materials," Composites Part B: Engineering vol. 90, pp. 58-68, 2016.

[19] B.K. Ahna, W.A. Curtina, T.A. Parthasarathy, and R.E. Dutton, "Criteria for crack deflection/penetration criteria for fiber-reinforced ceramic matrix composites," Composites Science and Technology, vol. 58, pp. 1775-1784, 1998.

[20] T. Stephan, "TOF-SIMS in Cosmochemistry," Planetary and Space Science, vol. 49, pp. 859-906, 2001.

[21] A. Kelly and W.R. Tyson, "Tensile Properties of Fibre-Reinforced Metals: Copper/Tungsten and Copper/Molybdenum," Journal of the Mechanics and Physics of Solids, vol. 13, pp. 329-350, 1965.

[22] M. Elkington, D. Bloom, C. Ward, A. Chatzimichall, and K. Potter "Hand-layup: understanding the manual process," Advanced Manufacturing: Polymer \& Composites Science vol. 1, pp. 138-151, 2015.

[23] A. Benninghoven, "Surface Investigation of Solids by the Statical Method of Secondary Ion Mass Spectroscopy (SIMS)," Surface Science, vol. 35, pp. 427-457, 1973. 